\title{
A ATUAÇÃO DOS IFS FRENTE AO SISTEMA NACIONAL DE PÓS-GRADUAÇÃO - UM COMPARATIVO ENTRE 2008 - 2014
}

\author{
C. G. M. ALVES ${ }^{*}$ e J. C. DEL PINO \\ Universidade Federal do Rio Grande do Sul - UFRGS \\ carinamessias@hotmail.com*
}

Artigo submetido em maio/2015 e aceito em julho/2015

DOI: $10.15628 /$ holos.2015.3090

\section{RESUMO}

A Rede Federal de Educação Profissional, Científica e Tecnológica foi instituída em 2008, juntamente com a criação dos Institutos Federais de Educação, Ciência e Tecnologia - IFs, por meio da Lei no 11.892/2008. O objetivo do presente estudo é analisar a atuação dos IFs no Sistema Nacional de Pós-Graduação - SNPG, fazendo um comparativo da oferta de cursos de pós-graduação stricto sensu antes e após a promulgação da referida Lei. Trata-se de uma pesquisa bibliográfica e documental, a metodologia usada foi de natureza quantitativa por meio da análise dos dados dos Cursos de Pós-Graduação stricto sensu recomendados pela Coordenação de Aperfeiçoamento de Pessoal de Nível Superior - CAPES, no período anterior a 2008 e até 2014, fornecidos pela Diretoria de Avaliação /CAPES. Concluiu-se que, com a criação dos IFs (oriundos da agregação/transformação de antigas instituições de educação profissional) aumentou a atuação das instituições de educação profissional no SNPG, tendo em vista o crescimento de $186 \%$ do número de IFs ofertando cursos de PósGraduação stricto sensu, e o aumento de $414 \%$ desses cursos no período de 2008 a 2014. A área de avaliação com maior número de cursos pós-graduação é a área de Ensino, com um pequeno predomínio de cursos de pósgraduação na modalidade profissional em comparação com a modalidade acadêmica.

PALAVRAS-CHAVE: Educação Profissional, Institutos Federais de Educação, Ciência e Tecnologia, Sistema Nacional de Pós-Graduação.

\section{THE PERFORMANCE OF IFS IN THE NATIONAL POSTGRADUATE SYSTEM - A COMPARISON BETWEEN 2008 - 2014}

\begin{abstract}
The Professional Education, Science and Technology Federal Network was established in 2008, along with the creation of the Federal Institutes of Education, Science and Technology - IFs by means of Law no. 11.892/2008. The aim of this study is to analyze the performance of IFs in the National Postgraduate System - SNPG, making a comparative of post-graduate stricto sensu courses offering before and after the enactment of the said Law. It's a bibliographical research and document the methodology used was quantitative nature through data's analysis of Postgraduate stricto sensu Courses recommended by the CAPES, in the period before 2008
\end{abstract}

and until 2014, provided by the Direction of Evaluation / CAPES. It was concluded that, with the creation of IFs (derived from the aggregation / transformation of old professional education institutions) the activity of professional education institutions in SNPG increased, owing to $186 \%$ growth of IFs numbers that offering Postgraduate stricto sensu courses, and an $414 \%$ increase of postgraduate courses in the period 2008 to 2014. The assessment area with the largest number of postgraduate courses is the science education, with a predominance of small postgraduate courses in professional mode compared with the academic mode.

KEYWORDS: Professional Education, Federal Institutions of Education, Science and Technology's, National Postgraduate System. 


\section{INTRODUÇÃO}

Em 2009, foi comemorado o centenário da Rede Federal da Educação Profissional no Brasil. O marco inicial da Rede é o Decreto no 7.566, de 23 de Setembro de 1909, que instaurou 19 Escolas de Aprendizes Artífices, dando origem à Rede Federal que culminou nas Escolas Técnicas Federais e, posteriormente, nos Centros Federais de Educação Tecnológica - CEFETs e atuais Institutos Federais de Educação, Ciência e Tecnologia - IFs (KUNZE, 2009).

De acordo com Parecer CNE/CEB 16/1999, a partir de 1942, surgiram as Escolas Industriais e Técnicas, com o objetivo de oferecer a formação profissional em nível equivalente ao do secundário. No ano de 1959, as Escolas Industriais e Técnicas passaram à categoria de autarquias e foram denominadas Escolas Técnicas Federais. Em 1978, três delas se transformaram em Centros Federais de Educação Tecnológica, constituindo os CEFETs do Rio de Janeiro, Paraná e Minas Gerais (BRASIL, 1999).

Em 2007, iniciou-se o processo de criação dos IFs, que culminou com a Lei 11.892, de 29 de dezembro de 2008. A referida Lei instituiu a Rede Federal de Educação Profissional, Científica e Tecnológica e criou os Institutos Federais de Educação, Ciência e Tecnologia, dando início à reorganização na Rede Federal de Educação Profissional.

Atualmente a Rede Federal de Educação Profissional, Científica e Tecnológica é constituída pelas seguintes instituições: Institutos Federais de Educação, Ciência e Tecnologia - IFs; Universidade Tecnológica Federal do Paraná - UTFPR; Centro Federal de Educação Tecnológica Celso Suckow da Fonseca - CEFET-RJ e o Centro Federal de Educação Tecnológica Minas Gerais CEFET-MG; Escolas Técnicas vinculadas às Universidades Federais e o Colégio Pedro II.

Foram criados 38 Institutos Federais de Educação, Ciência e Tecnologia. Esses IFs foram oriundos de CEFETs, Unidades de Ensino Descentralizadas - UNEDs, Escolas Agrotécnicas, Escolas Vinculadas às Universidades Federais e Escolas Técnicas Federais.

De acordo com a Lei no 11.892/08, art. 2으, os IFs são instituições de educação superior, básica e profissional, pluricurriculares e multicampi, especializados na oferta de educação profissional e tecnológica nas diferentes modalidades de ensino, com base na conjugação de conhecimentos técnicos e tecnológicos com as suas práticas pedagógicas.

Nos incisos do art. 60 da Lei $\mathrm{n} 011.892 / 08$, que tratam das finalidades e características dos IFs, fica evidente a preocupação com uma proposta de instituição que ofereça educação profissional e tecnológica em todos os níveis e modalidades de ensino, incluindo aí a oferta de cursos de Pós-Graduação stricto sensu.

A partir da análise das finalidades, características e objetivos dos IFs surge a questão de como está sendo a atuação dessas instituições frente ao Sistema Nacional de Pós-Graduação SNPG coordenado pela Coordenação de Aperfeiçoamento de Pessoal de Nível Superior - CAPES.

Este estudo propõe verificar como a criação dos IFs (oriundos da agregação/transformação de antigas instituições de educação profissional) impactou na oferta de cursos de pós-graduação stricto sensu, fazendo um comparativo da atuação dessas instituições no SNPG antes e após a promulgação da Lei 11.892/98, ou seja, antes de 2008 e até 2014. 


\section{A CAPES E O SISTEMA NACIONAL DE PÓS-GRADUAÇÃO}

Instituída em 1951, por meio do Decreto no 29.741, de 11 de julho de 1951, a Coordenação de Aperfeiçoamento de Pessoal de Nível Superior - CAPES, fundação pública vinculada ao Ministério da Educação, na época denominada de Campanha Nacional de Aperfeiçoamento de Pessoal de Nível Superior tinha como objetivo principal "assegurar a existência de pessoal especializado em quantidade e qualidade suficientes para atender às necessidades dos empreendimentos públicos e privados que visam ao desenvolvimento econômico e social do país e oferecer aos indivíduos mais capazes, sem recursos próprios, acesso a todas as oportunidades de aperfeiçoamentos" (BRASIL, 1951).

A CAPES foi criada num momento em que persistia a tendência a um modelo de ensino superior baseado em escolas profissionais que abrigavam cerca de 50 mil alunos, nas quais a Pós-Graduação stricto sensu era praticamente inexistente. Sua criação significou a iniciativa do Estado brasileiro de se equipar de órgãos e instrumentos para a regulação de diferentes aspectos da vida nacional e para a formulação e execução de políticas que lhe permitissem cumprir um projeto de industrialização intensiva do país (MARTINS, 2002. p. 296-297).

Segundo Martins (2002), em seu período inicial a CAPES promoveu uma série de iniciativas que tiveram impacto imediato na melhoria do ensino superior e permitiram a implantação futura da Pós-Graduação nacional. Além disso, a CAPES forneceu bolsas de estudo no país, de modo a viabilizar a participação de estudantes nesses cursos, principalmente aqueles vindos de regiões menos favorecidas academicamente; paralelamente, promoveu a reciclagem de docentes, através de centros regionais de treinamento e procurou também enviar alunos para fazer Pós-Graduação no exterior. No final dos anos 50, inúmeros estudantes e docentes estavam de volta ao Brasil e nos anos subsequentes assumiriam a liderança intelectual e científica nas universidades, participando ativamente da implantação dos primeiros cursos de mestrado e de doutorado no país.

Em 1964, a antiga Campanha transformou-se em Coordenação de Aperfeiçoamento de Pessoal de Nível Superior e começou a dar os primeiros passos para atuar como agência de fomento de Pós-Graduação, passando a ser subordinada diretamente ao Ministério da Educação e Cultura e orientada por um Conselho Deliberativo que detinha o poder decisório.

A partir do modelo posto em prática nos Estados Unidos da América, as características da Pós-Graduação brasileira foram fixadas pelo Parecer CFE no 977/65, conhecido como "Parecer Sucupira", elaborado pelo professor Newton Sucupira, aprovado pelo Conselho Federal de Educação. O parecer foi fruto de uma solicitação de Flávio Suplicy de Lacerda, Ministro da Educação durante o governo de Castelo Branco, em face à ausência de informação sobre a natureza dos cursos de Pós-Graduação.

O Parecer 977/65, que teve Newton Sucupira como relator, veio conceituar os cursos de Pós-Graduação, distinguindo dois tipos de Pós-Graduação: stricto sensu e lato sensu. Na primeira categoria, incluiu o mestrado e o doutorado, cujo objetivo seria de natureza acadêmica, de pesquisa e de cultura, tendo como compromisso o avanço do saber. Esses cursos, ligados à essência da universidade, deveriam constituir atividades regulares e permanentes e conferir diplomas de mestre e de doutor, sendo que esse último corresponderia ao nível mais elevado 
na hierarquia dos cursos superiores. Por sua vez, o Parecer atribuía à PósGraduação lato sensu um objetivo eminentemente prático, conferindo um certificado ao seu final (MARTINS, 2002. p. 300).

Em 1973, foi criado o Grupo de Trabalho para sugerir medidas para a formulação de uma política nacional de Pós-Graduação. Esse grupo propôs a criação do Conselho Nacional de PósGraduação - CNPG, órgão interministerial responsável pela formulação e execução da política geral de Pós-Graduação. O Conselho Nacional de Pós-Graduação recebeu a incumbência de elaborar o 10 Plano Nacional de Pós-Graduação (I PNPG), aprovado em 11 de novembro de 1974, para o período 1974-79.

O objetivo central do I PNPG era a expansão da Pós-Graduação, visando à capacitação dos docentes das instituições de ensino superior e suas principais metas eram o aumento da titulação e de vagas nos cursos de mestrado e de doutorado.

A CAPES passou a desempenhar um papel importante na implantação da política de Pós-Graduação delineada pelo I PNPG, ao assumir a responsabilidade de organizar o Programa Institucional de Capacitação Docente (PICD), cujo objetivo era estimular as instituições de ensino superior a desenvolver seus recursos humanos por meio de cursos de Pós-Graduação stricto sensu (MARTINS, 2002. p. 302).

O CNPG foi extinto em 1981 e suas atribuições passaram para a CAPES, que gradativamente deixou de ser um órgão de distribuição de bolsas e começou a se transformar efetivamente em agência de fomento para os programas de Pós-Graduação.

A instituição se fortaleceu. A CAPES foi reconhecida como órgão responsável pela elaboração do Plano Nacional de Pós-Graduação stricto sensu, em 1981, pelo Decreto no 86.791, de 28 de dezembro de 1981. Foi também reconhecida como Agência Executiva do Ministério da Educação e Cultura junto ao Sistema Nacional de Ciência e Tecnologia, cabendo-lhe elaborar, avaliar, acompanhar e coordenar as atividades relativas ao ensino superior.

Em 1990, a CAPES foi estabelecida pela Lei no 8.028, de 12 de abril de 1990 como órgão específico do Ministério da Educação. Posteriormente, a Lei no 8.405, de 9 de janeiro de 1992, permitiu ao Poder Executivo instituir a CAPES como Fundação Pública, atribuindo à instituição maior força para desempenhar o acompanhamento e avaliação dos cursos de Pós-Graduação stricto sensu no Brasil.

Com o fortalecimento da instituição, a CAPES emitiu, na década de 90, a Portaria no. 47, de 17 de outubro de 1995 que determinou a implantação de procedimentos apropriados para a recomendação, acompanhamento e avaliação dos cursos de mestrado voltados para a formação profissional. Assim surgia a modalidade de cursos de pós-graduação stricto sensu profissional. Em Janeiro de 1999, a CAPES publicou a Portaria no. 80 que dispôs sobre o reconhecimento dos mestrados profissionais desde que cumpridos determinados requisitos.

Após mais de 50 anos de criação, a Lei no 11.502, de 11 de julho de 2007 cria uma Nova CAPES, que até então era responsável pela coordenação do Sistema Nacional de Pós-Graduação SNPG, e recebeu o desafio de indução e fomento da formação inicial e continuada de professores para a educação básica. 
Desde sua criação, a CAPES vem desempenhando um papel fundamental na expansão e consolidação da Pós-Graduação stricto sensu (mestrados profissionais e mestrados e doutorados acadêmicos).

Atualmente, a CAPES tem por finalidade subsidiar o Ministério da Educação na formulação de políticas e desenvolvimento de atividades de suporte à formação de profissionais de magistério para a educação básica e superior e para o desenvolvimento científico e tecnológico do país. Conforme o artigo 1ㅇ do seu estatuto, no âmbito da educação superior, a CAPES tem como finalidade subsidiar o Ministério da Educação na formulação de políticas para Pós-Graduação, coordenar o sistema de Pós-Graduação e avaliar os cursos desse nível, e estimular, mediante bolsas de estudo, auxílios e outros mecanismos, a formação de recursos humanos altamente qualificados para a docência de grau superior, a pesquisa e o atendimento da demanda dos setores público e privado.

\subsection{Modalidade de Cursos de Pós-Graduação Stricto Sensu}

No que se refere ao Sistema Nacional de Pós-Graduação - SNPG é importante discorrer sobre as modalidades de cursos no nível pós-graduação stricto sensu que compõe o SNPG, que são as: modalidades acadêmicas e profissionais.

A modalidade de Pós-Graduação stricto sensu acadêmica é a modalidade considerada mais tradicional. É composta pelos níveis de mestrado e doutorado e o objetivo é formar pesquisadores com o foco inicial na academia. De acordo com o Parecer CFE no 977/65, a modalidade de pósgraduação stricto sensu acadêmica tem por finalidade proporcionar formação científica ou cultural ampla e aprofundada, desenvolvendo a capacidade de pesquisa e poder criados nos diferentes ramos do saber.

A modalidade de pós-graduação stricto sensu profissional é considerada recente, mesmo o Parecer CFE no 977/65 já propondo a criação de cursos de pós-graduação orientados à capacitação profissional, a existência legal enquanto prática acadêmica institucionalizada decorre da década de 90.

A diferença entre as duas modalidades de Cursos de Pós-graduação é que a modalidade profissional é a designação do mestrado profissional com ênfase em estudos e técnicas diretamente voltadas ao desempenho de um alto nível de qualificação profissional. Esta ênfase é uma das diferenças em relação aos Cursos de Pós-Graduação Acadêmicos. (Parecer CNE/CES 79/2002).

A principal diferença entre o mestrado acadêmico (MA) e o MP é o produto, isto é, o resultado almejado. No MA, pretende-se pela imersão na pesquisa formar, a longo prazo, um pesquisador. No MP, também deve ocorrer a imersão na pesquisa, mas o objetivo é formar alguém que, no mundo profissional externo à academia, saiba localizar, reconhecer, identificar e, sobretudo, utilizar a pesquisa de modo a agregar valor a suas atividades, sejam essas de interesse mais pessoal ou mais social. Com tais características, o MP aponta para uma clara diferença no perfil do candidato a esse mestrado e do candidato ao mestrado acadêmico (RIBEIRO, 2005. P. 15). 
O mestrado profissional teve sua primeira regulamentação pela CAPES por meio da Portaria CAPES no 47, de 17 de outubro de 1995.

O mestrado profissional nasce regulamentado desde 1995, seguindo-se portarias e resoluções que tentam estabelecer as diferenças entre cursos acadêmicos e profissionais. Com formato e denominação polêmicos, o MP esbarra na concepção acadêmica da pós-graduação, sedimentada por práticas e modelos tradicionais (FISCHER, 2005, p. 25).

Os Cursos de pós-graduação profissionais e acadêmicos possuem características distintas e buscam formar profissionais para atuar tanto no mundo do trabalho quanto na academia. A titulação do mestrado profissional nada difere do mestrado acadêmico e as duas modalidades possuem as mesmas prerrogativas.

O curso de MP goza das mesmas prerrogativas de outros mestrados, sendo este também o entendimento do órgão superior de ensino do país. De acordo com esse entendimento, o título obtido em um MP dá os mesmos direitos, em termos de carreira acadêmica, que os usufruídos por detentores de mestrados acadêmico-científicos (BRASIL, 2002).

De acordo com Fischer (2005), uma das diferenças é que o Mestrado Profissional não se trata de um tipo de formação pensada em termos de linhas de pesquisa, mas em termos de área de competência para a solução de problemas e para a inovação. No entanto, este foco não deve ser motivo para criar uma hierarquização entre mestrados acadêmicos e profissionais. As duas modalidades estão no mesmo nível hierárquico.

Mestrados profissionais não são cursos não acadêmicos, já que existem principalmente nos espaços da academia. A inércia estrutural da pós-graduação brasileira e a hipervalorização do mestrado acadêmico por muito tempo, acentuada pelo esforço que as áreas aplicadas fazem no sentido de constituírem e serem valorizadas como produtores de pesquisa e conhecimento, criou uma rejeição ao formato diferenciado do MP (FISCHER, 2005, p. 25).

Uma importante diferença que deve ser destacada é a falta do nível de doutorado na modalidade profissional. Atualmente é importante pensar neste novo nível como sinal de amadurecimento da pós-graduação profissional.

A modalidade que ainda não existe é o doutorado profissional (DP) que deve merecer um apoio especial estimulando-se a criação de cursos com desenho inovador que preserve as características essenciais de um doutorado, mas que incorpore a prática como elemento estruturante das teorias. $O$ doutorado é um novo desafio para a academia, pois há uma forte aderência entre o que se espera de profissionais que estarão liderando estrategicamente o desenvolvimento brasileiro e o que a Universidade pode contribuir para a formação destes (FISCHER, WAIANDT; FONSECA, 2011, p. 12).

Desde o seu início a pós-graduação brasileira vive uma espécie de síndrome bipolar entre valores, padrões e critérios de ensino e avaliação estritamente acadêmicos e as exigências de formação do mundo do trabalho. O mestrado profissional surgiu como uma forma mais visível 
dessa disputa entre lideranças da comunidade acadêmica e das instituições que defendem tradições ou inovações como se fossem mutuamente exclusivas.

Para Fischer, Waiandt e Fonseca (2011) as instituições formam pesquisadores e professores com grande experiência. Contudo, mais desafiador e interessante nestes novos tempos que resgatam ideais desenvolvimentistas é formar profissionais para o mundo do trabalho. Desta forma, programas profissionais são experiências de inovação e reinvenção das práticas acadêmicas.

A Portaria CAPES no 80/98, trazia como objetivo do mestrado profissional, "a formação de profissionais pós-graduados aptos a elaborar novas técnicas e processos, com desempenho diferenciado de egressos dos cursos de mestrado que visem preferencialmente um aprofundamento de conhecimentos ou técnicas de pesquisa científica, tecnológica ou artística".

Onze anos depois, a Portaria Normativa MEC no 17, de 28 de dezembro de 2009, amplia a atuação do mestrado profissional, trazendo como objetivos:

I - capacitar profissionais qualificados para o exercício da prática profissional avançada e transformadora de procedimentos, visando atender demandas sociais, organizacionais ou profissionais e do mercado de trabalho; II - transferir conhecimento para a sociedade, atendendo demandas específicas e de arranjos produtivos com vistas ao desenvolvimento nacional, regional ou local; III promover a articulação integrada da formação profissional com entidades demandantes de naturezas diversas, visando melhorar a eficácia e a eficiência das organizações públicas e privadas por meio da solução de problemas e geração e aplicação de processos de inovação apropriados; IV - contribuir para agregar competitividade e aumentar a produtividade em empresas, organizações públicas e privadas (BRASIL, 2009).

Portaria Normativa MEC no 17/2009 também transforma o mestrado profissional em política de Estado com indução para cursos em rede nacional, regula a oferta de curso mediante chamadas públicas, implanta avaliação distinta dos cursos acadêmicos, permite a atuação de docentes que não tenha o título de doutor, mas que tenha reconhecida experiência profissional e amplia os formatos de trabalho de conclusão de curso dos alunos que vão além da dissertação.

Com relação ao fomento de cursos na modalidade profissional, a Portaria MEC no 17/2009 restringe a concessão de bolsas de estudos para mestrados profissionais em áreas priorizadas: "salvo em áreas excepcionalmente priorizadas, o mestrado profissional não pressupõe, a qualquer título, a concessão de bolsas de estudos pela CAPES" (art. 11).

Atualmente os programas priorizados e contemplados com bolsas de estudos são os Mestrados Profissionais em Rede Nacional - PROFs voltados para formação de professores da Educação Básica. Os PROFs são cursos de pós-graduação stricto sensu, em forma associativa (em rede), induzidos pela CAPES, com oferta nacional, realizados por uma rede de instituições de ensino superior (IES) e centros de pesquisa no âmbito do Sistema Universidade Aberta do Brasil UAB.

Além dos professores matriculados nos PROFs, existe a previsão de concessão de bolsas de estudos para os professores da Rede Pública da Educação Básica, regularmente matriculados em 
cursos de mestrado profissional ofertados pelas instituições de ensino superior, devidamente recomendados pela CAPES, conforme Portarias CAPES n.o 289 e 478 de 2011.

Apesar dos avanços que a Portaria MEC no 17/2009 trouxe para fortalecimento do mestrado profissional, permaneceram algumas lacunas com relação à modalidade acadêmica, como o fomento aos programas e a concessão de bolsas. Essas lacunas podem representar um entrave no crescimento desta modalidade.

De acordo com Fischer, Waiandt e Fonseca (2011), a instituição da modalidade da pósgraduação stricto sensu na modalidade profissional é fruto da política empreendida pelo governo federal a partir dos anos 2000 na tentativa de configurar a educação profissional como um eixo conformativo, institucionalizando-se tanto nos Institutos Federais de Ciência e Tecnologia com todos os níveis de ensino (da educação básica à pós-graduação) quanto nas Instituições Educacionais públicas e privadas com os mestrados profissionais.

Nesse sentido, merece destaque o V PNPG 2005/2010 que estimulou o fortalecimento de quadros para mercados "não acadêmicos" (BRASIL, 2004), especificando as empresas, os órgãos de governo e organizações não governamentais e movimentos sociais, como as instituições alvo dos egressos da pós-graduação.

Neste contexto de fortalecimento da pós-graduação stricto sensu voltada para o exercício da prática profissional é importante destacar a importância da atuação das instituições da Rede Federal de Educação Profissional, Científica e Tecnológica no SNPG.

\section{CONTEXTO HISTÓRICO DA REDE FEDERAL DE EDUCAÇÃO PROFISSIONAL, CIENTÍFICA E TECNOLÓGICA E CRIAÇÃO DOS INSTITUTOS FEDERAIS DE EDUCAÇÃO, CIÊNCIA E TECNOLOGIA}

A Rede Federal de Educação Profissional, Científica e Tecnológica, instituída em 2008, originou-se a partir das primeiras escolas de caráter profissional no Brasil, as Escolas de Aprendizes Artífices, criadas em 1909, pelo Decreto no 7.566/1909 do presidente Nilo Peçanha. Segundo Manfredi (2002), foi criada uma rede de 19 Escolas de Aprendizes Artífices, dando origem à rede federal que culminou nas Escolas Técnicas e, posteriormente, nos CEFETs. Essas escolas eram voltadas para o ensino profissional, primário e gratuito destinada aos "desafortunados" ou "desvalidos da sorte".

De acordo com Freitas e Batista (2013), a Constituição Brasileira de 1937 foi a primeira constituição a tratar especificamente de ensino técnico, profissional e industrial, estabelecendo em seu artigo 129 que:

O ensino pré-vocacional profissional destinado às classes menos favorecidas é, em matéria de educação, o primeiro dever de Estado. Cumpre-Ihe dar execução a esse dever, fundando institutos de ensino profissional e subsidiando os de iniciativa dos Estados, dos Municípios e dos indivíduos ou associações particulares e profissionais. É dever das indústrias e dos sindicatos econômicos criar, na esfera de sua especialidade, escolas de aprendizes, destinadas aos filhos de seus operários ou de seus associados. A lei regulará o cumprimento desse dever e os 
poderes que caberão ao Estado sobre essas escolas, bem como os auxílios, facilidades e subsídios a lhes serem concedidos pelo Poder Público (BRASIL, 1937).

Em 1937, as Escolas de Aprendizes Artífices passaram a ser conhecidas como Liceus Industriais. Posteriormente, em 1942, os Liceus tornaram-se Escolas Industriais e Técnicas e ofereciam a formação profissional em nível equivalente ao secundário (LIMA, 2012).

Em 1959, as Escolas Industriais e Técnicas foram denominadas Escolas Técnicas Federais ETF, na forma de autarquias com autonomia didática e de gestão. O objetivo dessas escolas é ampliado para "proporcionar base de cultura geral e iniciação técnica que permitam ao educando integrar-se na comunidade e participar do trabalho produtivo ou prosseguir seus estudos" (BRASIL, 1959).

Em 1978, com as Escolas Técnicas Federais do Paraná, de Minas Gerais e do Rio de Janeiro são transformadas em Centros Federais de Educação Tecnológica - CEFETs, equiparando estas instituições profissionais aos centros universitários, no âmbito da educação superior (SILVA, 2009).

A expansão dos CEFETs continua durante a década de 90, período em que várias outras escolas técnicas e agrotécnicas federais tornam-se CEFETs.

Em 1994, por meio da Lei no 8.948, de 8 de dezembro de 1994, que dispõe sobre a instituição do Sistema Nacional de Educação Tecnológica, as Escolas Técnicas Federais e as Escolas Agrotécnicas Federais transformam-se gradativamente em CEFETs, mediante decreto específico para cada instituição.

Quando a proposta dos IFs surgiu, o objetivo dos CEFETs era transformar-se em universidades tecnológicas, a exemplo do que aconteceu com o CEFET do Paraná, transformado em Universidade Tecnológica Federal do Paraná - UTFPR por meio da Lei 11.184, de 7 de outubro de 2005. Diante disso, em 2007, iniciou-se o processo de criação dos Institutos Federais de Educação, Ciência e Tecnologia - IFs, que seriam oriundos da transformação dos Centros Federais de Educação Tecnológica - CEFETs.

O primeiro dispositivo legal a tratar do tema da criação dos IFs foi o Decreto no 6.095, de 24 de abril de 2007. De acordo com este decreto, o objetivo do Ministério da Educação era estimular o processo de reorganização das instituições federais de educação profissional e tecnológica, a fim de que atuassem de forma integrada regionalmente e que esta reorganização seria pelo modelo de Instituto Federal de Educação, Ciência e Tecnologia. (BRASIL, 2007).

De acordo com dados da Secretaria de Educação Profissional e Tecnológica do Ministério da Educação - SETEC/MEC, quando iniciou o processo de criação dos IFs a Rede Federal de Ensino Tecnológico contava com 36 Escolas Agrotécnicas, 33 CEFETs com suas 58 Unidades de Ensino Descentralizadas (UNEDs), 32 Escolas Vinculadas, uma Universidade Tecnológica Federal e uma Escola Técnica Federal (BRASIL, 2008).

Em 12 de dezembro de 2007, o Ministério da Educação emitiu a Chamada Pública MEC/SETEC 02/2007, com o objetivo de acolher, num prazo de 90 dias, propostas de constituição dos IFs. O primeiro item da contextualização da chamada pública expressa a intencionalidade política do projeto: 
A implantação dos Institutos Federais de Educação, Ciência e Tecnologia constituise em uma das ações de maior relevo do Plano de Desenvolvimento da Educação - PDE, na medida em que tornará mais substantiva a contribuição da rede federal de educação profissional e tecnológica ao desenvolvimento sócio-econômico do conjunto de regiões dispostas no território brasileiro, a partir do acolhimento de um público historicamente colocado a margem das políticas de formação para o trabalho, da pesquisa aplicada destinada à elevação do potencial das atividades produtivas locais e da democratização do conhecimento à comunidade em todas as suas representações (BRASIL, 2007b).

O resultado da Chamada Pública foi publicado por meio da Portaria MEC/SETEC N ${ }^{\circ} 116$, de 31 de março de 2008. De acordo com Otranto (2010), apenas os CEFETs de Minas Gerais e Rio de Janeiro não aderiram à proposta de transformação em IFs, pois o objetivo desses CEFETs continuava sendo a transformação em Universidade Tecnológica.

Em junho de 2008, foi lançado o documento "Concepções e Diretrizes dos Institutos Federais de Educação, Ciência e Tecnologia", o qual apresentava os fundamentos dos Institutos, e em dezembro foram criados os Institutos Federais de Educação, Ciência e Tecnologia e instituída a Rede Federal de Educação Profissional, Científica e Tecnológica, por meio da Lei № 11.892, de 29 de dezembro de 2008.

O termo Rede Federal de Educação Profissional e Tecnológica é utilizada como referência a um conjunto de instituições federais, vinculadas ao MEC, voltadas para a educação profissional e tecnológica em nível médio e superior.

$\mathrm{Na}$ acepção da lei, trata-se de uma rede, pois congrega um conjunto de instituições com objetivos similares, que devem interagir de forma colaborativa, construindo a trama de suas ações tendo como fios as demandas de desenvolvimento socioeconômico e inclusão social. Federal por estar presente em todo o território nacional, além de ser mantida e controlada por órgãos da esfera federal. De educação por sua centralidade nos processos formativos. A palavra educação está adjetivada por profissional, científica e tecnológica pela assunção de seu foco em uma profissionalização que se dá ao mesmo tempo pelas dimensões da ciência e da tecnologia, pela indissociabilidade da prática com a teoria (SILVA, 2009. p.16).

Criada inicialmente com objetivo de atender as "classes menos favorecidas", a Rede Federal de Educação Profissional, Científica e Tecnológica se configura atualmente como importante estrutura com a finalidade para ofertar educação profissional e tecnológica, em todos os seus níveis e modalidades. O objetivo das Instituições que compõe a Rede é formar e qualificar cidadãos com vistas na atuação profissional nos diversos setores da economia, com ênfase no desenvolvimento socioeconômico local, regional e nacional.

\section{A ATUAÇÃO DOS IFS NO SISTEMA NACIONAL DE PÓS-GRADUAÇÃO.}

De acordo com o documento "Concepção e Diretrizes dos Institutos Federais de Educação, Ciência e Tecnologia", produzidos pela SETEC/MEC, em junho de 2008, os Institutos Federais devem atuar em todos os níveis e modalidades da educação profissional, com estreito 
compromisso com o desenvolvimento integral do cidadão trabalhador. Ainda de acordo com este documento, a organização curricular dos Institutos Federais traz para os profissionais da educação um espaço ímpar de construção de saberes. Por terem esses profissionais a possibilidade de dialogar simultaneamente, e de forma articulada, da educação básica até a pós-graduação, trazendo a formação profissional como paradigma nuclear.

A lei no 11.892/08 criou 38 IFs, com a finalidade de ofertar educação profissional e tecnológica em todos os níveis e modalidades e promover a integração e a verticalização da educação profissional, desde a educação básica até a educação superior, otimizando a infraestrutura física, os quadros de pessoal e os recursos de gestão (OTRANTO, 2010. p. 101).

As finalidades e características dos IFs estão previsto na Lei no 11.892, de 29 de dezembro de 2008, em seu art. 6ㅇ, e cabe destaque os incisos I e II que tratam sobre a atuação em todos os níveis e modalidades de ensino com forco na educação profissional e tecnológica: "I - ofertar educação profissional e tecnológica, em todos os seus níveis e modalidades, formando e qualificando cidadãos com vistas na atuação profissional nos diversos setores da economia, com ênfase no desenvolvimento socioeconômico local, regional e nacional; II - desenvolver a educação profissional e tecnológica como processo educativo e investigativo de geração e adaptação de soluções técnicas e tecnológicas às demandas sociais e peculiaridades regionais".

No artigo 7으, onde a referida Lei trata dos objetivos dos IFs, percebe-se que a temática oferta de cursos em todos os níveis e modalidades é enfatizada novamente, quando faz referência ao objetivo em ministrar cursos de formação inicial e continuada de trabalhadores, objetivando a capacitação, o aperfeiçoamento, a especialização e a atualização de profissionais, em todos os níveis de escolaridade, nas áreas da educação profissional e tecnológica.

Ainda em seu artigo 70, incisos IV, alínea e, traz como um dos objetivos IFs: "VI - ministrar em nível de educação superior: e) cursos de pós-graduação stricto sensu de mestrado e doutorado, que contribuam para promover o estabelecimento de bases sólidas em educação, ciência e tecnologia, com vistas no processo de geração e inovação tecnológica".

Os dispositivos legais deixam claro a importância da atuação dos IFs no SNPG por meio da oferta de cursos de pós-graduação stricto sensu. De acordo com Pacheco (2010), o principal objetivo dos IFs é a profissionalização. O foco deve ser a formação para o exercício profissional tanto para os trabalhadores que necessitam para a realização de suas atividades profissionais de formação em nível superior, como para os que precisam da formação em nível médio técnico, e também para aqueles que atuam em qualificações profissionais mais especializadas, ao mesmo tempo, as atividades de pesquisa e extensão estão diretamente relacionadas ao mundo do trabalho.

A estruturação da oferta educativa passa pelo processo de identificação dos ingredientes tecnológicos básicos do curso - bases tecnológicas -; dos arranjos lógicos constituídos por essas bases - matrizes tecnológicas -; e da linha central que perpassa transversalmente essas matrizes sustentando a organização curricular e a identidade dos cursos, imprimindo a direção dos seus projetos pedagógicos - eixo tecnológico.(...) Essas mesmas observações cabem para os cursos de especialização lato-sensu e, no caso da pós-graduação stricto-sensu, 
torna relevante à oferta de mestrados e doutorados profissionais (PACHECO, 2010. p 23).

Levando em consideração o que diz Pacheco (2010) sobre a atuação dos IFs na profissionalização, uma reflexão que precisa ser feita é se os Institutos deveriam focar na oferta de Pós-graduação stricto sensu profissional. Analisando os objetivos dos IFs, dispostos na Lei 11.892/2008, observa-se que há uma adequação aos objetivos do mestrado profissional expresso na Portaria Normativa MEC no 17/2009 no que refere-se à realização de pesquisas aplicadas, estimulando o desenvolvimento de soluções técnicas e tecnológicas e desenvolvimento de atividades de extensão de acordo com os princípios e finalidades da educação profissional e tecnológica, em articulação com o mundo do trabalho e os segmentos sociais, e com ênfase na produção, desenvolvimento e difusão de conhecimentos científicos e tecnológicos (Quadro 1).

Quadro 1: Objetivos Institutos Federais de Educação, Ciência e Tecnologia e do Mestrado Profissional.

Objetivos dos IFs (art. 7으) - Lei 11.892/2008

I. ministrar educação profissional técnica de nível médio, prioritariamente na forma de cursos integrados, para os concluintes do ensino fundamental e para o público da educação de jovens e adultos;

II. ministrar cursos de formação inicial e continuada de trabalhadores, objetivando a capacitação, o aperfeiçoamento, a especialização e a atualização de profissionais, em todos os níveis de escolaridade, nas áreas da educação profissional e tecnológica;

III. realizar pesquisas aplicadas, estimulando o desenvolvimento de soluções técnicas e tecnológicas, estendendo seus benefícios à comunidade;

IV. desenvolver atividades de extensão de acordo com os princípios e finalidades da educação profissional e tecnológica, em articulação com o mundo do trabalho e os segmentos sociais, e com ênfase na produção, desenvolvimento e difusão de conhecimentos científicos e tecnológicos;

V. estimular e apoiar processos educativos que levem à geração de trabalho e renda e à emancipação do cidadão na perspectiva do desenvolvimento socioeconômico local e regional; e

VI. ministrar em nível de educação superior:

a) cursos superiores de tecnologia visando à formação de profissionais para os diferentes setores da economia;

b) cursos de licenciatura, bem como programas especiais de formação pedagógica, com vistas na formação de professores para a educação básica, sobretudo nas áreas de ciências e matemática, e para a educação profissional;

c) cursos de bacharelado e engenharia, visando à formação de profissionais para os diferentes setores da economia e áreas do conhecimento;

d) cursos de pós-graduação lato sensu de aperfeiçoamento e especialização, visando à formação de especialistas nas diferentes áreas do conhecimento; e

e) cursos de pós-graduação stricto sensu de mestrado e doutorado, que contribuam para promover o estabelecimento de bases sólidas em educação, ciência e tecnologia, com vistas no processo de geração e inovação tecnológica.
Objetivos do Mestrado

Profissional (art. 4) - Portaria MEC 17/2009

I. capacitar profissionais qualificados para o exercício da prática profissional avançada e transformadora

de procedimentos, visando atender demandas sociais, organizacionais ou profissionais e do mercado de trabalho;

II. transferir conhecimento para a sociedade, atendendo demandas específicas e de arranjos produtivos com vistas ao desenvolvimento nacional, regional ou local;

III. promover a articulação integrada da formação profissional com entidades demandantes de naturezas diversas, visando melhorar a eficácia e a eficiência das organizações públicas e privadas por meio da solução de problemas e geração e aplicação de processos de inovação apropriados;

IV. contribuir para agregar competitividade e aumentar a produtividade em empresas, organizações públicas e privadas. 
No entanto, cabe ressaltar que dentre os objetivos dos IFs não há nenhum impedimento da oferta de cursos de Pós-graduação stricto sensu na modalidade acadêmica. Muito pelo contrário, tendo em vista que a Lei 11.892/2008 prevê a oferta de doutorados pelos IFs (alínea e, Inciso IV, do artigo 7ㅇ). Como atualmente não existe doutorado na modalidade profissional, é natural que os Institutos se interessem pela modalidade acadêmica. Além da questão da falta do nível do doutorado profissional, há também uma análise que precisa ser feita de como a política de concessão fomento e bolsas de estudo pela CAPES, que é restrita na pós-graduação profissional, pode refletir na procura dos IFs pela modalidade acadêmica.

As Instituições de Educação Profissional e Tecnológica buscam encontrar o seu espaço e se configurar como um eixo de formação que articula ofertas de ensino que vão da educação à PósGraduação. No entanto, mesmo dotados de autonomia pedagógica e de gestão, e com o objetivo de ofertar cursos em todos os níveis da educação profissional e tecnológica, o papel dos IFs no SNPG ainda gera discussão por parte da comunidade científica e do governo.

Existe uma tensão sobre a oferta da Pós-graduação stricto sensu nos IFs e este fato deu origem ao Manifesto dos reitores dos Institutos Federais, que defendiam os IFs como instituições competentes para ofertar cursos de pós-graduação stricto sensu sem perder sua identidade, aprovado na 35a Reunião Ordinária do Conselho Nacional das Instituições da Rede Federal de Educação Profissional, Científica e Tecnológica (CONIF), realizada de 6 a 8 de agosto de 2013 em Natal (RN).

Após a repercussão deste manifesto, foi realizado na CAPES em 19 de maio de 2014 o seminário, cujo tema foi: A Rede Federal de Educação Profissional, Científica e Tecnológica no Sistema Nacional de Pós-Graduação realizado em Brasília. O Objetivo do seminário foi discutir a importância do fortalecimento das políticas voltadas para o trabalho das instituições da Rede Federal na oferta da pós-graduação e do papel da Capes neste contexto.

\section{METODOLOGIA}

Segundo Lakatos \& Marconi (2003), a metodologia é considerada como o conjunto das atividades sistemáticas e racionais que, com maior segurança e economia, permite alcançar o objetivo, traçando o caminho a ser seguido, detectando erros e auxiliando as decisões do cientista.

O presente estudo é caracterizado como pesquisa bibliográfica, que se deu por meio da análise das informações obtidas por revisão de literatura. De acordo com Vergara (2005) a pesquisa bibliográfica consiste em um estudo sistematizado desenvolvido em material publicado em livros, revistas, jornais e redes eletrônicas, isto é, material acessível ao público em geral.

Adotou-se também a pesquisa documental tendo em vista que foram levantados informações e dados que fazem parte do Sistema Nacional de Pós-Graduação e documentos disponibilizados pela Diretoria de Avaliação da CAPES. Para Vergara (2005), a pesquisa documental é a realizada em documentos conservados no interior de órgãos públicos e privados de qualquer natureza, ou com pessoas registros canais, regulamentos, circulares, ofícios, memorandos, balancetes, comunicações informais, filmes, microfilmes, fotografias, videoteipe, informações em disquete, diários, cartas pessoais e outros. 
Para analisar a atuação dos Institutos Federais de Educação, Ciência e Tecnologia (oriundos da agregação/transformação de antigas instituições de educação profissional) no Sistema Nacional de Pós-Graduação, a metodologia adotada nessa pesquisa foi de natureza quantitativa, com base nos dados fornecidos pela Diretoria de Avaliação da CAPES.

O método quantitativo, como o próprio nome indica, caracteriza-se pelo emprego da quantificação tanto nas modalidades de coleta de informações, quanto no tratamento delas por meio de técnicas estatísticas, desde as mais simples como as mais complexas (RICHARDSON et al 1999, p. 70).

A interpretação dos dados é basal na técnica da pesquisa quantitativa e serviu para análise dos dados sobre cursos de pós-graduação stricto sensu ofertados pelos IFs.

A Coleta de dados se deu por meio do levantamento de dados e informações sobre propostas de cursos de pós-graduação submetidas à avaliação da CAPES pelos IFs e cursos de PósGraduação stricto sensu ofertados nos IFs recomendados pela CAPES até 2008 e entre 2008 e 2014. Este período foi definido tendo em vista a criação dos IFs em 2008. Os dados foram extraídos do SNPG, fornecidos pela Diretoria de Avaliação - DAV da CAPES. O estudo foi composto pelos $38 \mathrm{IFs}$ e pelos 36 cursos de pós-graduação stricto sensu, oferecidos por estes IFs, e recomendados pela CAPES até a Avaliação de Propostas de Cursos Novos - APCN 2013 que teve sua análise concluída em agosto de 2014.

\section{RESULTADOS E DISCUSSÃO}

Analisar a atuação dos IFs frente ao Sistema Nacional de Pós-Graduação é o objetivo deste trabalho. Para isso verificou-se como a criação dos IFs (oriundos da agregação/transformação de antigas instituições profissionais) impactou na oferta de cursos de pós-graduação stricto sensu, fazendo um comparativo da atuação dessas instituições no SNPG antes e após a promulgação da Lei $11.892 / 2008$.

O primeiro curso de pós-graduação stricto sensu oferecido por um IF foi o Programa de Pós-Graduação em Engenharia de Materiais, nível mestrado acadêmico, do Instituto Federal do Maranhão - IFMA, criado mediante integração do Centro Federal de Educação Tecnológica do Maranhão e das Escolas Agrotécnicas Federais de Codó, de São Luís e de São Raimundo das Mangabeiras. Este curso foi recomendado pela CAPES em 2004.

Até 2008, dos 38 IFs, criados pela Lei no 11.892/98, apenas 7 instituições atuavam no SNPG, oferecendo cursos de Pós-Graduação stricto sensu, são elas: IFSC, IFRJ, IFMA/MC, IFF, IFES. IFSP, IFCE. Isso representava $18 \%$ dos institutos.

Já em 2014, seis anos após a criação dos Institutos Federais de Educação, Ciência e Tecnologia, dos 38 IFs, 20 atuavam no SNPG, oferecendo cursos de Pós-Graduação stricto sensu, representando $53 \%$ dos institutos. (Figura 1 ). 


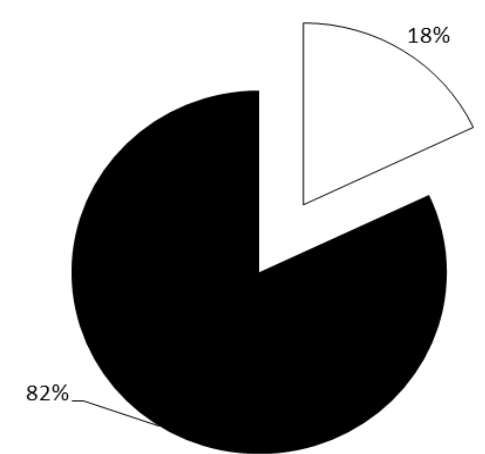

a) 2008
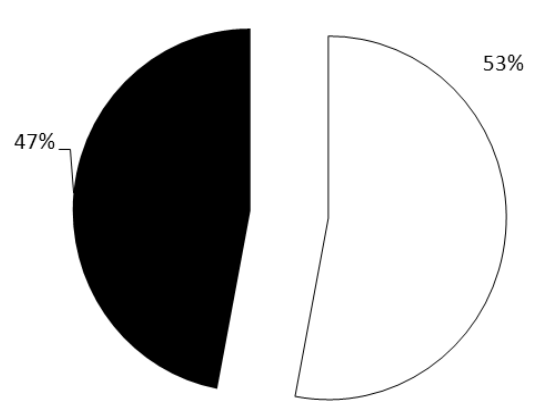

$\square$ IFETs atuando no SNPG

- IFETs não atuando no SNPG

b) 2014

Figura 1 - Atuação dos IFs no SNPG no período: a) 2008 a b) 2014. (Fonte: SNPG/DAV/CAPES).

Observa-se um crescimento do número dos IFs que passam a atuar no SNPG, a partir da promulgação da Lei 11.892/2008, passando de 7 para 20 instituições em 6 anos. Este crescimento foi verificado tanto no número de instituições que passaram a atuar no Sistema Nacional de PósGraduação, quanto no número de cursos ofertados pelos IFs. Em 2008 os IFs contavam com 7 cursos de Pós-graduação stricto sensu, já em 2014, passou a contar com 36 cursos de pósgraduação stricto sensu (Figura 2). Este fato pode ser explicado devido a um dos objetivos dos IFs, expresso na Lei 11.892/2008, que é a oferta de cursos de pós-graduação stricto sensu de mestrado e doutorado.

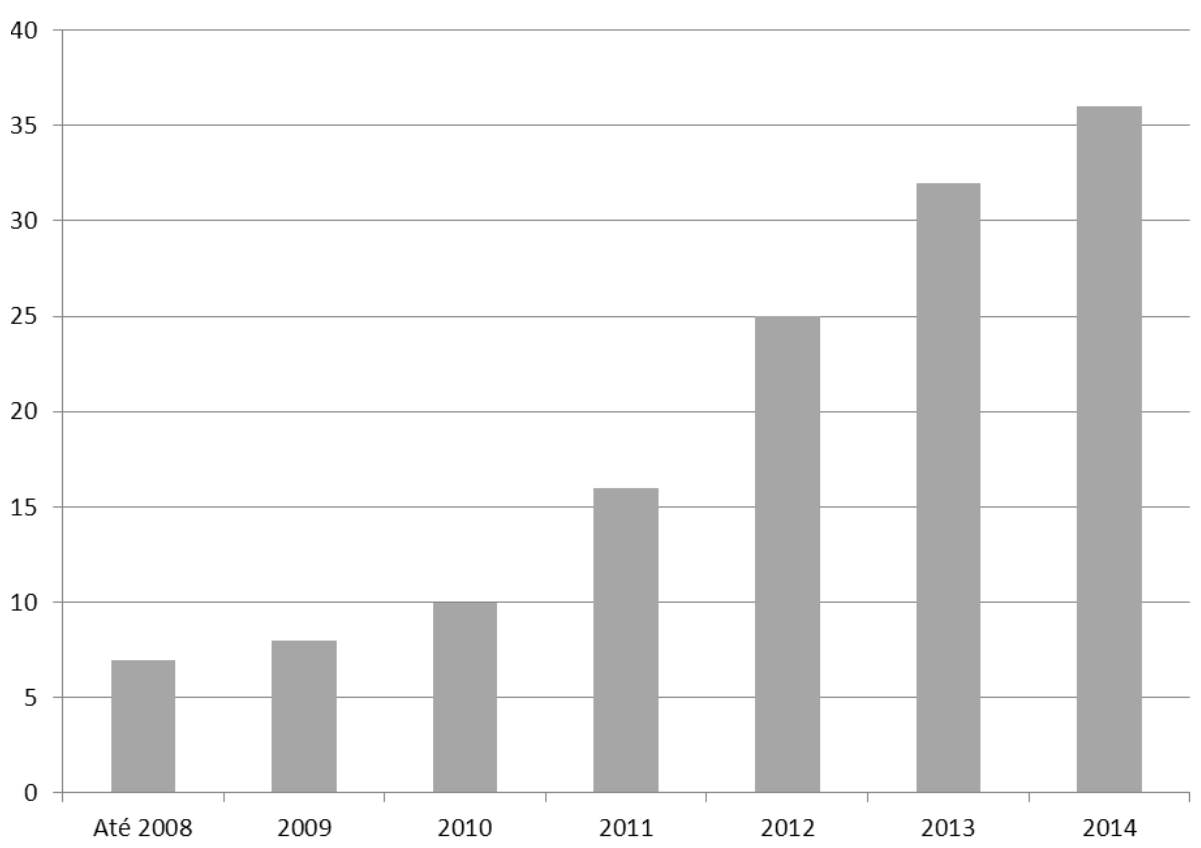

Figura 2 - Crescimento acumulado dos cursos de Pós-Graduação oferecidos pelos IFs no período 2008 a 2014.

(Fonte: SNPG/DAV/CAPES).

Comparando o crescimento dos cursos de Pós-graduação stricto sensu ofertados pelos IFs e o crescimento da oferta de cursos de pós-graduação no país, verifica-se que o crescimento dos cursos nos IFs é muito maior. Enquanto a quantidade de cursos recomendados pela CAPES cresceu 46\% entre 2008 e 2014, passando de 3893 cursos em 2008 para 5690 em 2014 (Figura 3), nos IFs este crescimento foi de $414 \%$ no mesmo período. 


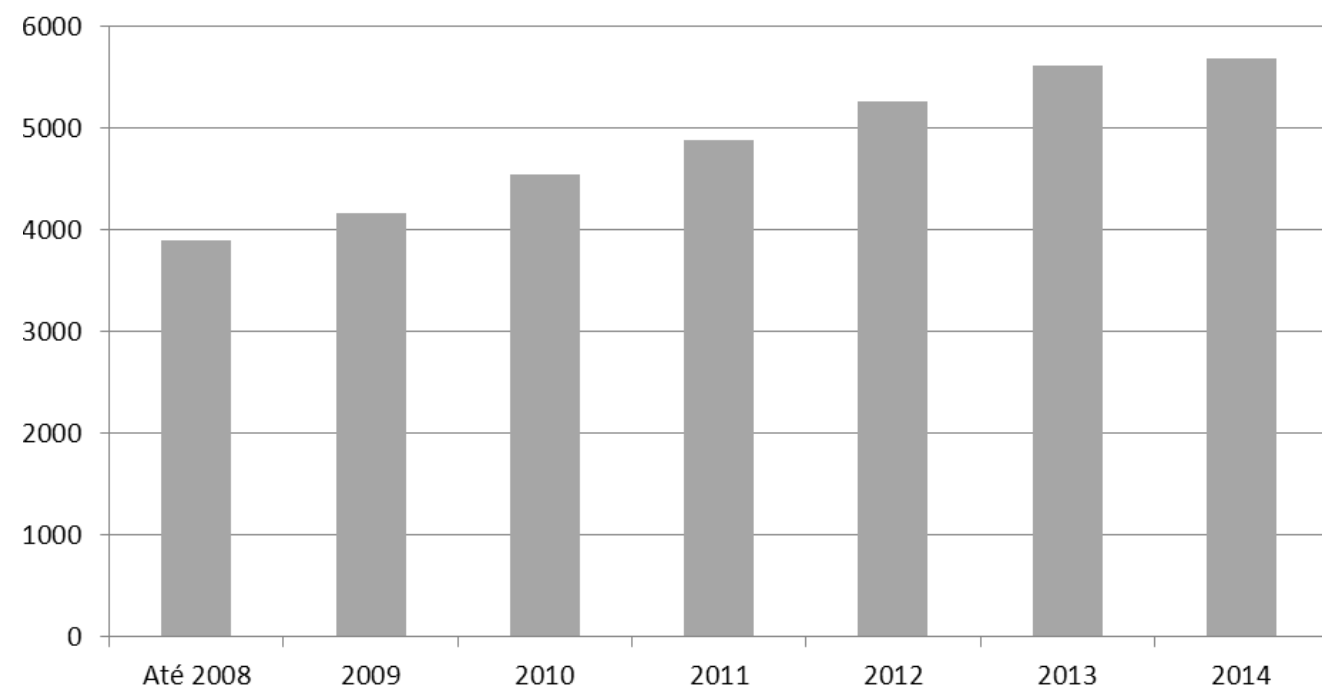

Figura 3 - Crescimento acumulado dos cursos de Pós-Graduação stricto sensu recomendados pela CAPES no período 2008 a 2014. (Fonte: SNPG/DAV/CAPES).

Tendo em vista que uma das finalidades dos IFs é a oferta de educação profissional e tecnológica em todos os níveis, além do número de cursos de Pós-Graduação stricto sensu oferecidos pelos IFS, um dado que precisa ser analisado é a modalidade de cursos de pósgraduação que essas instituições estão oferecendo.

O primeiro curso de pós-graduação stricto sensu na modalidade profissional oferecido por IF só foi recomendado em 2006, que foi o curso de Pós-graduação em Engenharia Ambiental do Instituto Federal Fluminense - IFF, criado mediante transformação do Centro Federal de Educação Tecnológica de Campos - CEFET/Campos.

Com relação à modalidade de cursos de pós-graduação oferecido pelos IFs, até 2008 , dos 7 cursos de Pós-graduação recomendados pela CAPES, 3 cursos pertenciam à modalidade acadêmica e 4 cursos à modalidade profissional. Em 2014, dos 36 cursos de pós-graduação, 17 cursos pertenciam à modalidade acadêmica e 19 cursos à modalidade profissional.

Em 2014 o número de cursos de pós-graduação stricto sensu oferecidos pelos IFs é 5 vezes maior do que em 2008, no entanto, juntamente com este crescimento, percebe-se uma diminuição no percentual de cursos de pós-graduação na modalidade profissional em relação à modalidade acadêmica, que passou de 57\% em 2008 para 53\% em 2014(Figura 4)..

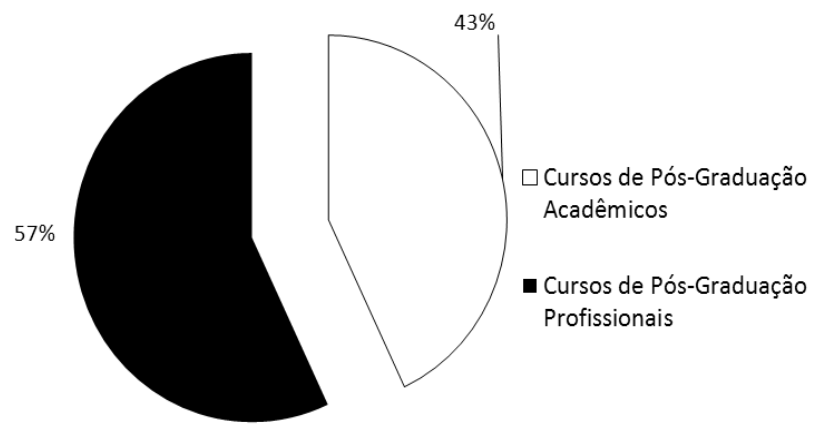

a) 2008

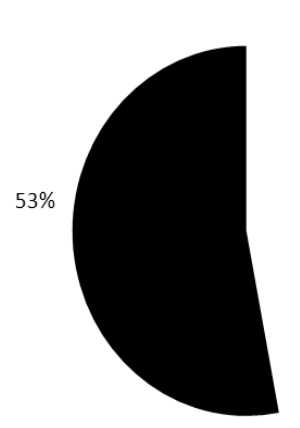

b) 2014

Figura 4 - Comparação entre as modalidades (Acadêmicos e Profissionais) dos cursos de pós-graduação oferecidos pelos IFs no período: a) 2008 a b) 2014. (Fonte: SNPG/DAV/CAPES). 
É importante destacar que apesar dos IFs concentrarem maior parte dos cursos de PósGraduação stricto sensu na modalidade profissional, considerando à submissão de propostas de cursos novos à avaliação da CAPES pelos IFs no APCN 2013, observa-se que há uma procura maior dos IFs por cursos de pós-graduação stricto sensu na modalidade acadêmica em detrimento da modalidade profissional, tendo em vista que das 21 propostas, apenas 7 foram de mestrado profissional (Figura 5).

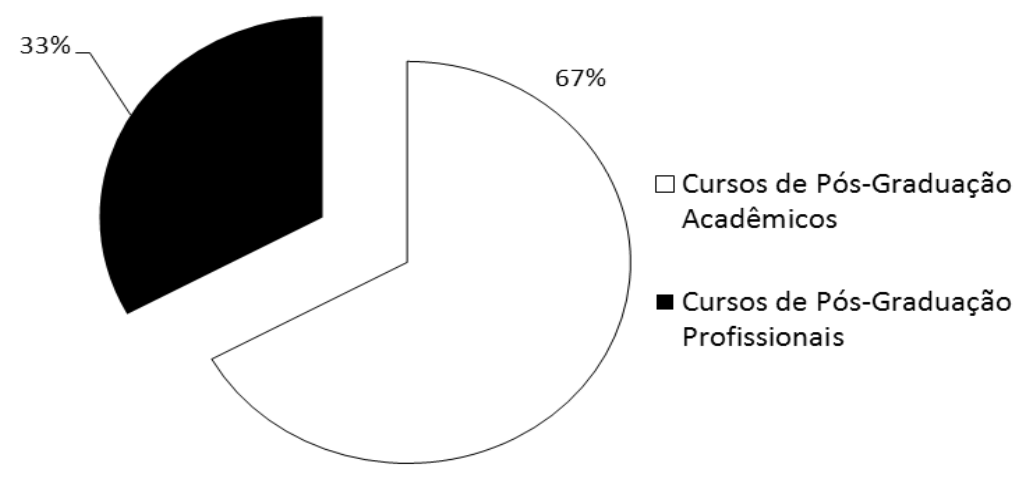

Figura 5 - Comparação da modalidade das Propostas de Cursos Novos de Pós-graduação (Acadêmicos e Profissionais) submetidos pelos IFs no APCN 2013. (Fonte: SNPG/DAV/CAPES).

Esta procura maior por cursos na modalidade acadêmica pode ser interpretada como um reflexo da limitação de concessão de bolsas de estudos para a modalidade profissional, prevista na Portaria MEC no 17/2009: "salvo em áreas excepcionalmente priorizadas, o mestrado profissional não pressupõe, a qualquer título, a concessão de bolsas de estudos pela CAPES" (art. 11). Apenas áreas de interesse do Estado, que atualmente estão relacionadas à cursos de pós-graduação stricto sensu profissionais voltados para formação de professores da Rede pública atuando na educação básica, recebem bolsas de estudos.

Analisando a área de conhecimento que os IFs atuam dentro do SNPG, verificou-se que até 2008 as áreas de Engenharias concentravam maior parte dos cursos de pós-graduação stricto sensu (Tabela 1).

Tabela 1: Distribuição dos cursos de pós-graduação stricto sensu oferecidos pelos Institutos Federais de Educação, Ciência e Tecnologia por área de avaliação no ano de 2008. Fonte: SNPG/DAV/CAPES

\begin{tabular}{cccc}
\hline Áreas de Avaliação & Cursos Acadêmicos & Cursos Profissionais & № de Cursos de PPGs \\
\hline Engenharias I & 1 & 1 & 2 \\
Engenharias II & 2 & 0 & 2 \\
Engenharias III & 0 & 2 & 2 \\
Ensino & 0 & 1 & 1 \\
\hline Total & 3 & 4 & 7 \\
\hline
\end{tabular}

Já em 2014, a área de Ensino passou a concentrar a maior parte dos cursos de PósGraduação stricto sensu (Tabela 2). Esse aumento de cursos na área de Ensino pode ser explicado devido a um dos objetivos dos Institutos Federais de Educação, Ciência e Tecnologia, previstas no artigo 7으, da Lei no 11.892/2008, que é ministrar "cursos de pós-graduação stricto sensu de mestrado e doutorado, que contribuam para promover o estabelecimento de bases sólidas em educação, ciência e tecnologia". Outro marco na área de Ensino foi a reformulação da área ocorrida em 2011, por meio da Portaria CAPES no 83, de 6 de junho de 2011. Isto pode ter 
refletido no número de cursos de pós-graduação stricto sensu ofertado por IF tendo em vista que 5 dos 7 cursos de pós-graduação da área de Ensino foram recomendados entre 2012 e 2014.

Tabela 2: Distribuição dos cursos de pós-graduação stricto sensu oferecidos pelos Institutos Federais de Educação, Ciência e Tecnologia por área de avaliação no ano de 2014. Fonte: SNPG/DAV/CAPES

\begin{tabular}{cccc}
\hline Áreas de Avaliação & Cursos Acadêmicos & Cursos Profissionais & No de Cursos \\
\hline Ensino & 1 & 6 & 7 \\
Ciência de Alimentos & 2 & 3 & 5 \\
Ciências Agrárias & 3 & 1 & 4 \\
Engenharias II & 3 & 0 & 3 \\
Engenharias III & 1 & 2 & 3 \\
Interdisciplinar & 1 & 2 & 3 \\
Educação & 1 & 2 & 3 \\
Engenharias I & 1 & 1 & 2 \\
Engenharias IV & 2 & 0 & 2 \\
Ciências Ambientais & 0 & 2 & 2 \\
Zootecnia/Recursos Pesqueiros & 1 & 0 & 1 \\
Ciências da Computação & 1 & 0 & 1 \\
\hline Total & 17 & 19 & 36 \\
\hline
\end{tabular}

Quando se compara a distribuição dos cursos de Pós-graduação stricto sensu dos IFs por grande área de avaliação e modalidade (acadêmico e profissional), em 2008, a maior parte dos cursos se concentrava na grande área de Engenharias, que é composta pelas áreas de Engenharias I, Engenharias II, Engenharias III e Engenharias IV (Figura 6), com uma divisão homogênea entre as modalidades acadêmicas e profissionais.

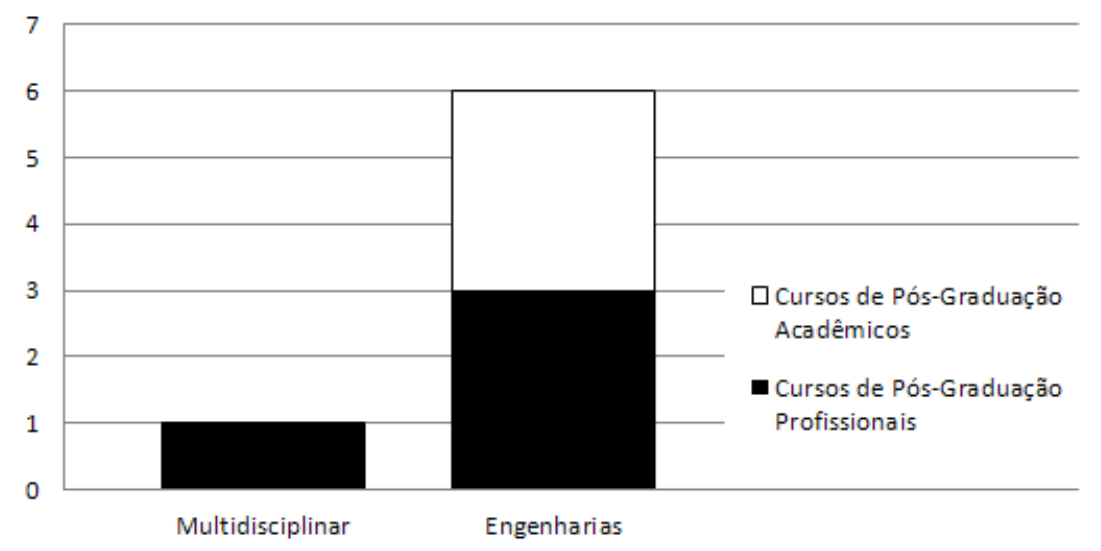

Figura 6 - Cursos de pós-graduação oferecidos pelos IFs por modalidade e grande área de avaliação no ano de 2008. (Fonte: SNPG/DAV/CAPES).

Em 2014, a maior parte dos de cursos de Pós-Graduação stricto sensu ofertados nos IFs se concentra na grande área Multidisciplinar, que é composta pelas áreas Interdisciplinar, Ensino, Ciências Ambientais, Materiais e Biotecnologia, com um predomínio na modalidade Profissional. Esta concentração de cursos na modalidade profissional se evidencia também na grande área de Ciências Humanas, ao contrário das grandes áreas de Engenharias, Ciências Agrárias e Ciências Exatas e da Terra em que há um predomínio de cursos na modalidade Acadêmica. Verificou-se também que os IFs não ofertam cursos nas grandes áreas de Ciências Biológicas, Ciências da Saúde, Ciências Sociais aplicadas e Linguística, Letras e Artes. (Figura 7). 


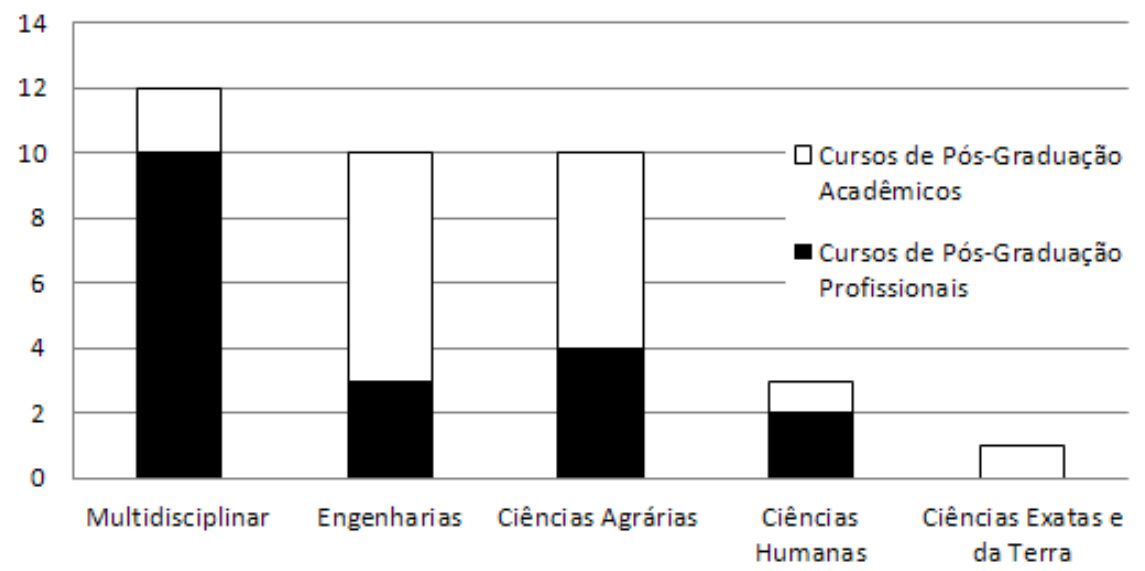

Figura 7 - Cursos de pós-graduação oferecidos pelos IFs por modalidade e grande área de avaliação no ano de 2014. (Fonte: SNPG/DAV/CAPES).

Dentre as características e finalidades dos IFs, está a oferta de ensino superior de graduação e de pós-graduação na área tecnológica. Considerando os dados de 2014, que revelam que a grande área de avaliação que concentra maior parte dos programas de Pós-Graduação stricto sensu ofertados pelos IFs é a grande área de Multidisciplinar, deixando para trás a grande área de Engenharias, isto se caracteriza como um impacto da Lei 11.892/2008, tendo em vista que outra finalidade expressa na referida lei é qualificar os IFs como centro de referência no apoio à oferta do ensino de ciências nas instituições públicas de ensino, oferecendo capacitação técnica e atualização pedagógica aos docentes das redes públicas de ensino.

Além de atuar na área tecnológica, verifica-se com o crescimento dos cursos de pósgraduação na área de Ensino que, com a criação dos IFs houve também um fortalecimento do papel das instituições de educação profissional na formação de pessoal de nível superior que atuará na área de Educação, ou seja, na formação de professores.

\section{CONSIDERAÇÕES FINAIS}

Atuando em todos os estados brasileiros, os Institutos Federais de Educação, Ciência e Tecnologia - IFs têm por objetivos a formação de recursos humanos e produção do conhecimento, da oferta de educação superior, básica e profissional, especializados na oferta de educação profissional e tecnológica nas diferentes modalidades de ensino.

A partir da análise das finalidades, características e objetivos dos IFs, verificou-se por meio deste estudo que a criação dos Institutos Federais por meio da Lei no 11.892/2008 impactou na oferta de cursos de pós-graduação stricto sensu por essas instituições de Ensino. Este impacto pode ser comprovado pelo aumento de $186 \%$ do número de IFs que passaram a ofertar cursos de stricto sensu e pelo crescimento $414 \%$ de cursos de pós-graduação stricto sensu oferecidos nos IFs no período de 2008 a 2014.

Constatou-se que há um equilíbrio entre a modalidade de cursos de Pós-Graduação Acadêmicos e Profissionais, ressaltando no entanto, que de 2008 até 2014, na submissão de propostas de cursos novos no APCN 2013, a modalidade acadêmica representou $67 \%$ das propostas. A procura maior por cursos na modalidade acadêmica pelos IFs pode estar relacionada com a política de fomento dos mestrados profissionais prevista na Portaria MEC $n$ o 17/2009 que 
limita de concessão de bolsas de estudos para áreas priorizadas, como é o caso da área de formação de docentes.

O estudo revelou também que a atuação dos IFs no SNPG vai além das áreas tecnológica e profissional. Ter entre os objetivos previstos na Lei no 11.892/2008 ministrar cursos de pósgraduação stricto sensu de mestrado e doutorado, que contribuam para promover o estabelecimento de bases sólidas em educação, ciência e tecnologia e entre as finalidades o apoio à oferta do ensino de ciências nas instituições públicas de ensino foram alguns dos fatores que contribuíram para que a área de Ensino se configurasse atualmente como a área de avaliação que concentra maior parte dos cursos de pós-graduação stricto sensu recomendados pela CAPES oferecidos pelos IFs.

Este fato revela que os IFs se apresentam atualmente como um novo locus para a formação de professores, tanto em nível de graduação, como na oferta de cursos de pós-graduação stricto sensu.

Mesmo com a diversidade de opiniões sobre o papel dos Institutos Federais de Educação, Ciência e Tecnologia no Sistema Nacional de Pós-Graduação, este estudo comprovou que a atuação dos Institutos Federais no SNPG foi fortalecida pela Lei no 11.892/2008, refletindo no crescimento da oferta de cursos de pós-graduação stricto sensu, aumentando o reconhecimento dos IFS como instituições com competência para atuar em todos os níveis e modalidade de ensino.

\section{REFERÊNCIAS BIBLIOGRÁFICAS}

1. BRASIL. Decreto no 7.566, de 23 de setembro de 1909. Crêa nas capitaes dos Estados da Republica Escolas de Aprendizes Artifices, para o ensino profissional primario e gratuito. Rio de Janeiro, 1909. Disponível em <http://www6.senado.gov.br/legislacao/ListaNorma. action?numero=7566\&tipo_norma=DEC\&data=19090923\&link=s> Acesso em 03 fev. 2014.

2. Constituição dos Estados Unidos do Brasil, de 10 de novembro de 1937. Disponível em: http://www.planalto.gov.br/ccivil_03/Constituicao/Constitui\%C3\%A7ao37.htm>Acesso em 05 fev. 2014.

3. __ Decreto no 29.741, de 11 de julho de 1951. Institui uma Comissão para promover a Campanha Nacional de Aperfeiçoamento de pessoal de nível superior. 1951. Disponível em <http://www2.camara.leg.br/legin/fed/decret/1950-1959/decreto-29741-11-julho-1951336144-publicacaooriginal-1-pe.html> Acesso em: 22 fev. 2015.

4. __ Lei no 3.552, de 16 de fevereiro de 1959. Dispõe sobre nova organização escolar e administrativa dos estabelecimentos de ensino industrial do Ministério da Educação e Cultura, e dá outras providências. Rio de Janeiro, 1959. Disponível em <http://www.planalto.gov .br/ccivil_03/Leis/L3552.htm> Acesso em: 03 fev. 2014.

5. MEC/Conselho Federal de Educação. Parecer CFE n. 977, de 3 de dezembro de 1965. Definição dos Cursos de Pós-Graduação, 1965a. Disponível em <http://www.scielo.br/scielo.php?script=sci_arttext\&pid=S1413-24782005000300014> Acesso em 05 fev. 2014.

6. L L Lei no 8.948, de 8 de dezembro de 1994. Dispõe sobre a instituição do Sistema Nacional de Educação Tecnológica e dá outras providências. 1994. Disponível em 
<http://www.planalto.gov.br/ccivil_03/leis/L8948.htm> Acesso em: 03 fev. 2014.

7.

Lei no 9.394 de 1996. Estabelece as diretrizes e bases da educação nacional. Brasília, 1996. Disponível em < http://www.planalto.gov.br/ccivil_03/Leis/L9394.htm> Acesso em: 03 fev. 2014.

8. MEC/Conselho Nacional de Educação. Câmara de Educação Superior. Parecer CNE/CEB n.o 16, de 5 de outubro de 1999. Diretrizes Curriculares Nacionais para a Educação Profissional de Nível Médio, 1999a. Disponível em <http://portal.mec.gov.br/cne/arquivos/ pdf/1999/pceb016_99.pdf> 10 fev. 2014.

9. . MEC/Conselho Nacional de Educação. Câmara de Educação Superior. Parecer CNE/CES n. 79, de 12 de março de 2002. Consulta sobre titulação de programa de mestrado profissionalizante, 2002. Disponível em <http://portal.mec.gov.br/cne/arquivos/pdf/2002/ pces079_02.pdf>05 jun. 2014.

10.

MEC. Plano Nacional de Pós-graduação (PNPG) 2005-2010. Brasília: CAPES. Dezembro de 2004.

11.

Lei no 11.184, de 7 de outubro de 2005. Dispõe sobre a transformação do Centro Federal de Educação Tecnológica do Paraná em Universidade Tecnológica Federal do Paraná e dá outras providências. Brasília, 2005. Disponível em <http://www.planalto.gov.br/c civil_03/_Ato2004-2006/2005/Lei/L11184.htm> Acesso em: 03 fev. 2014.

12.

Decreto no 6.095, de 24 de abril de 2007. Estabelece diretrizes para o processo de integração de instituições federais de educação tecnológica, para fins de constituição dos Institutos Federais de Educação, Ciência e Tecnologia - IF, no âmbito da Rede Federal de Educação Tecnológica. Brasília, 2007a. Disponível em <http://www.planalto.gov.br/ccivil_03/_ ato2007-2010/2007/decreto/d6095.htm> Acesso em 08 out. 2013.

13.

Chamada Pública MEC/SETEC no 002/2007. Chamada Pública de Propostas para constituição dos Institutos Federais de Educação, Ciência e Tecnologia - IF. MEC/Brasília. 2007b. Disponível em <http://portal.mec.gov.br/arquivos/pdf/chamada_publica_IFs3.pdf> Acesso em 20 mar. 2014.

14. __. Lei no 11.892, de 29 de dezembro de 2008. Institui a Rede Federal de Educação Profissional, Científica e Tecnológica, cria os Institutos Federais de Educação, Ciência e Tecnologia, e dá outras providências. Brasília, 2008. Disponível em <http://www.planalto. gov.br/ccivil_03/_Ato2007-2010/2008/Lei/L11892.htm> Acesso em: 03 fev. 2013.

15. _. Portaria Normativa MEC no 17, de 28 de dezembro de 2009. Dispõe sobre o mestrado profissional no âmbito da Fundação Coordenação de Aperfeiçoamento de Pessoal de Nível Superior - CAPES, Brasília, 2011 Disponível em <http://capes.gov.br/images/stories/down load/avaliacao/avaliacao-n/Portaria-MEC-17-2009.pdf> Acesso em: 10 jan. 2015.

16. FISCHER, T. Mestrado profissional como prática acadêmica. RBPG - Revista Brasileira de PósGraduação, v. 2, n. 4, p. 24-29, jul. 2005.

17. FISCHER, Tania Maria Diederichs; WAIANDT, Claudiani; FONSECA, Renata Lara. Educação Profissional e Pós-Graduação: um desafio estratégico para transformação do espaço educacional In: III Encontro de Ensino e Pesquisa em Administração e Contabilidade - EnEPQ, João Pessoa, 2011. 
18. FREITAS, M. C. E; BATISTA, G. A. Currículo e Competências: Implicações para a Formação de Profissionais de Saúde. Revista Encontro de Pesquisa em Educação, Uberaba, v.1, n.1, p. 138152, 2013.

19. KUNZE, Nadia Cuiabano. O surgimento da rede federal de educação nos primórdios do regime republicano no Brasil. Revista Brasileira de Educação Profissional e Tecnológica/Ministério da Educação, Secretaria da Educação Profissional e Tecnológica. V.2, no 2 (nov.2009).Brasília: MEC, SETEC, 2009.

20. LAKATOS, E.; MARCONI, M. A. Fundamentos de metodologia científica. 5. ed. São Paulo: Atlas, 2003.

21. LIMA, Fernanda Bartoly Gonçalves de. A formação de professores nos Institutos Federais de Educação, Ciência e Tecnologia: um estudo da concepção política. Unb - Brasília, 2012.

22. MANFREDI. S. M. Educação Profissional no Brasil. São Paulo: Cortez, 2002.

23. MARTINS, Carlos Benedito. A CAPES e a formação do Sistema Nacional de Pós- Graduação. In: FERREIRA, Marieta de Moraes; In: MOREIRA, Regina da Luz. CAPES, 50 anos: depoimentos ao CPDOC/FGV. Brasília: CAPES, 2002. p. 295-310.

24. MINISTÉRIO DA EDUCAÇÃO. Secretaria de Educação profissional e Tecnológica. Um novo modelo de educação profissional e tecnológica: concepção e diretrizes. Brasília: SETEC/MEC, 2010. Disponível em <http://portal.mec.gov.br/index.php?option=com_content\&view=article \&id=12503\& Itemid=841> Acesso em 20 mar. 2014.

25. _ Concepções e diretrizes dos institutos federais de educação, ciência e tecnologia. Brasília: SETEC/MEC 2010. Disponível em: <http://redefederal.mec.gov.br/index.php?option $=$ com_content\&view=article\&id=55\&Itemid =50>. Acesso em: 14 de jan. de 2013.

26. OTRANTO, C. R. Criação e Implantação dos Institutos Federais de Educação, Ciência e Tecnologia - IFs . Revista Retta. UFRRJ/PPGEA, Seropédica, RJ: EDUR, Vol. I, no 01, jan./jun. 2010, p. 89-108.

27. PACHECO, Eliezer (org.) Institutos Federais: uma revolução na educação profissional e tecnológica. Brasília: SETEC/MEC, 2010 Disponível em <http://portal.mec.gov.br/index.php? option=com_content\&view=article\&id=12503\&Itemid=841> Acesso em 15 mar. 2014.

28. RIBEIRO, R. J. O mestrado profissional na política atual da CAPES. RBPG - Revista Brasileira de Pós-Graduação, Brasília, v. 2, n. 4, p. 8-15, jul. 2005. Seção Debates. Disponível em: <http://www2.capes.gov.br/rbpg/portal/conteudo/ Debates_Artigo1_n4.pdf>. Acesso em: 5 mar. 2008.

29. Mestrado profissional, mestrado acadêmico e doutorado. Disponível em: <http://www.CAPES.gov.br/images/stories/download/artigos/Artigo_30_08_07.pdf>. Acesso em: 15 out. 2008.

30. RICHARDSON, Roberto J. et al. Pesquisa social: métodos e técnicas. São Paulo: Atlas, 1999.

31. SILVA, Caetana Juracy (org.). Institutos Federais Lei 11.892, de 29/12/2008: Comentários e Reflexões. Natal: IFRN, 2009.

32. VergarA, Sylvia Constant. Métodos de pesquisa em administração. São Paulo: Atlas, 2005. 